\title{
Electronic structure and magnetic studies of V-doped ZnO: $a b$ initio and experimental investigations
}

\author{
N MAMOUNI ${ }^{1}$, J JUDITH VIJAYA ${ }^{2, *}$, A BENYOUSSEF ${ }^{1}$, A EL KENZ ${ }^{1}$ and M BOUOUDINA ${ }^{3,4}$ \\ ${ }^{1}$ LMPHE, Faculty of Sciences, Mohammed V University of Rabat, Rabat, Morocco \\ ${ }^{2}$ Catalysis and Nanomaterials Research Laboratory, Department of Chemistry, Loyola College, Chennai 600 034, India \\ ${ }^{3}$ Nanotechnology Centre, University of Bahrain, PO Box 32038, Zallaq, Kingdom of Bahrain \\ ${ }^{4}$ Department of Physics, College of Science, University of Bahrain, PO Box 32038, Zallaq, Kingdom of Bahrain \\ *Author for correspondence (jjvijaya78@gmail.com; jjvijayaloyola@yahoo.co.in)
}

MS received 4 August 2017; accepted 21 September 2017; published online 29 May 2018

\begin{abstract}
In this study, the electronic structure of $\mathrm{V}$-doped $\mathrm{ZnO}$ system is studied by means of density functional theory. Different concentrations of $\mathrm{V}$ and rising of Fermi level increase the relative occupation of majority/minority spin of $3 \mathrm{~d}$ state and also induce strong spin-splitting. The existence of three different states of $\mathrm{V}$ spin moment has been confirmed and is found to be concentration dependent. We found that $\mathrm{O}$ p-orbitals are responsible for the origin of the magnetic moment. Ruderman-Kittel-Kasuya-Yosida mechanism and the atomic spin polarization of $\mathrm{V}$ are the key factors for the appearance of ferromagnetism in $\mathrm{V}$-doped $\mathrm{ZnO}$ system. The synthesized nanoparticles exhibit hexagonal wurtzite crystal structure, where both crystallite size and lattice parameters vary with V content. Magnetic measurements at room temperature confirm the ferromagnetic behaviour of $\mathrm{V}$-doped $\mathrm{ZnO}$ system.
\end{abstract}

Keywords. Ab-initio calculation; band structure model; DMS; RKKY; ZnO.

\section{Introduction}

Mn-doped GaAs discovery with a ferromagnetic (FM) behaviour [1] has driven increasing interest in diluted ferromagnetic semiconductors (DMSs). Although III-V based DMSs such as GaAs:Mn have been successfully achieved, their low magnetic ordering temperatures $(170 \mathrm{~K})$ limit the application of such materials [2-6]. It is important to note that ferromagnetic semiconductors at room temperature are needed for practical applications of spintronics [7]. Magnetic impurities, like transition metals, may transform a semiconductor into a half-metal: the majority spinbands are metallic and the minority spin bands are semiconducting. Therefore at Fermi energy, it presents a complete spin polarized density of states (DOS), which is a required property to generate spintronic devices in electronic industries. The transition metal (TM)-doped DMSs based on II-VI, III-V, group IV and chalcopyrite [8-12] compound semiconductors have attracted great attention recently. There are different mechanisms proposed for the FM behaviour in DMSs, such as Ruderman-Kittel-KasuyaYosida (RKKY) model [13], double resonance mechanism [14], super-exchange mechanism [15], etc. in order to explain the observed ferromagnetism to the property of $3 \mathrm{~d}$-electrons arising from TM. Among them, $\mathrm{ZnO}$ doped with $\mathrm{TM}$ impurities has been studied extensively and its magnetic properties have been under investigation, as it shows the presence [16-22] or the absence [23-25] of ferromagnetism at room temperature. Although extensive theoretical works [16,26-28] were carried out on this system, a complete understanding of the nature of room temperature magnetism is still lacking [29]. From a physical/chemical point of view, $\mathrm{ZnO}$ is a very interesting material, because of its mixed covalent/ionic aspect in the chemical bonding.

$\mathrm{ZnO}$ exists in hexagonal wurtzite or cubic zinc blende structures. In general, all covalent semiconductors have tetrahedral coordination. Hence, single and double 3d TM-doped $\mathrm{ZnO}$ systems are currently under extensive investigation, in order to identity the FM behaviour using ab-initio electronic structure calculations based on the generalized gradient approximation. $\mathrm{ZnO}$ is a direct bandgap semiconductor $\left(E_{\mathrm{g}}=3.2 \mathrm{eV}\right)$ and when doped with transition metals, a FM ordering appears at room temperature. Also, $\mathrm{ZnO}$ can be easily prepared as a thin film, showing piezoelectric and electro-optic properties $[30,31]$.

The aim of this study is to report first-principles study of the electronic and magnetic properties of $\mathrm{ZnO}$ stabilized by various $\mathrm{V}$ concentrations. From the results, it is observed that $\mathrm{V}$-doping transforms $\mathrm{ZnO}$ from diamagnetism to ferromagnetism with a half-metallic character. By increasing the concentration of $\mathrm{V}$, the ground state is found to change from antiferromagnetic to FM. Hence, in this study, we have investigated the relationship between the structure and magnetic properties of V-doped $\mathrm{ZnO}$ nanoparticles. 


\section{Calculation method}

In this study, spin-polarized electronic properties and magnetic moments of $\mathrm{V}$-doped $\mathrm{ZnO}$ system with different $\mathrm{V}$ concentrations in the FM phase are presented. We used the KKR-CPA method in density functional theory (DFT) implemented in the MACHIKANEYAMA2002v08 package [32], by considering the Korringa-Kohn-Rostoker (KKR) Green's function method and the coherent potential approximation (CPA) combined with the parameterization of Vosko, Wilk and Nusair (VWN) [33]. The shape of the crystal is approximated using Muffin-tin potential and the wavefunctions were expanded up to $1=2$ in real harmonics ( 1 is the angular momentum quantum number at each site). Also, we have chosen $350 \mathrm{~K}$-points in the irreducible part of the first Brillouin zone. For different $\mathrm{V}$ concentrations, calculations based on hexagonal wurtzite crystal structure with the lattice parameters $a=3.180 \AA, c=5.166 \AA$ and unit vector $u=0.377$ were performed. The $\mathrm{ZnO}$ DOS is given in figure 1 .

We propose that $\mathrm{Zn}$ sites would be occupied by $\mathrm{V}$, and Curie temperature as a function of the impurities concentration $(c)$ is calculated by the mean field approximation (MFA) [34] given below:

$$
k_{\mathrm{B}} T_{\mathrm{C}}^{\mathrm{MFA}}=\frac{2}{3} \frac{E_{\mathrm{DLM}}^{\mathrm{CPA}}-E_{\mathrm{FR}}^{\mathrm{CPA}}}{c}
$$

We also calculated the total energies of $\mathrm{ZnVO}$ system between the FM state and the disordered local moment (DLM), e.g., $\mathrm{Zn}_{1-\mathrm{c}} \mathrm{TM}_{\uparrow \mathrm{c}} \mathrm{O}$ and the DLM system with 50\% TM moments

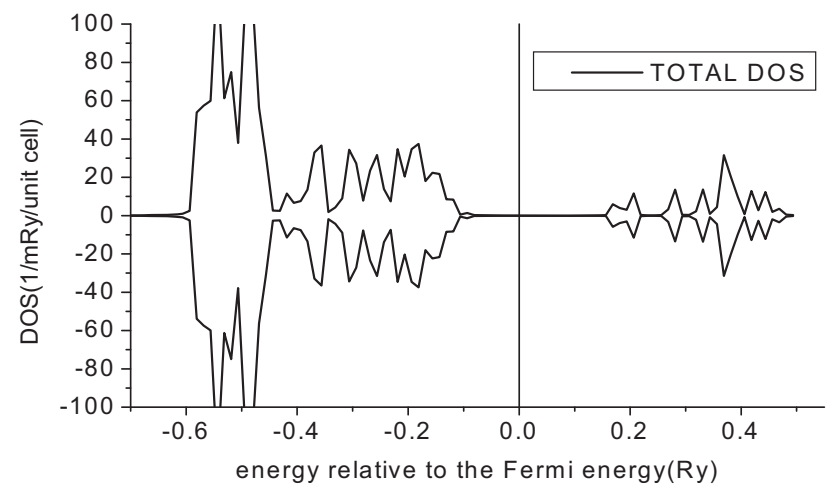

Figure 1. Total density of states of $\mathrm{ZnO}$. up and $50 \%$ down, i.e., $\mathrm{Zn}_{1-\mathrm{c}} \mathrm{TM}_{\uparrow \mathrm{c} / 2} \mathrm{TM}_{\downarrow \mathrm{c} / 2} \mathrm{O}$. The calculated energy difference $\Delta E=E_{\mathrm{DLM}}-E_{\mathrm{FM}}$ is shown in table 1. From the results, $\mathrm{Zn}_{0.95} \mathrm{~V}_{0.05} \mathrm{O}$ state showed more stability for FM states, i.e., the ferromagnetism is energetically favourable. We can see that the Curie temperature of the state $\mathrm{Zn}_{0.85} \mathrm{~V}_{0.15} \mathrm{O}$ is found to be $98.54(\mathrm{~K})$, which is lower than that of $\mathrm{Zn}_{0.95} \mathrm{~V}_{0.05} \mathrm{O}$ state.

\section{Experimental}

\subsection{Synthesis of pure and $\mathrm{V}$-doped $\mathrm{ZnO}$}

The typical synthesis procedure for pure and $\mathrm{V}$-doped $\left(\mathrm{V}^{5+}\right)$ $\mathrm{ZnO}\left(\mathrm{Zn}_{1-x} \mathrm{~V}_{x} \mathrm{O}\right)$ is as follows:

$0.2 \mathrm{~mol} \mathrm{l}^{-1}$ of zinc nitrate hexahydrate $\mathrm{Zn}\left(\mathrm{NO}_{3}\right)_{2} \cdot 6 \mathrm{H}_{2} \mathrm{O}$ and $\mathrm{NaHCO}_{3}$ were prepared separately using double-distilled water. $\mathrm{Zn}\left(\mathrm{NO}_{3}\right)_{2} \cdot 6 \mathrm{H}_{2} \mathrm{O}$ and ammonium metavanadate $\left(\mathrm{NH}_{4} \mathrm{VO}_{3}\right)$ were taken as the precursors of $\mathrm{Zn}$ and $\mathrm{V}$. $\mathrm{Zn}\left(\mathrm{NO}_{3}\right)_{2} \cdot 6 \mathrm{H}_{2} \mathrm{O}$ and $\mathrm{NaHCO}_{3}$ were dissolved separately in double-distilled water to obtain $0.2 \mathrm{~mol} \mathrm{l}^{-1}$ solutions. Zinc nitrate solution was then slowly added into vigorously stirred $\mathrm{NaHCO}_{3}$ and Triton-X 100 mixed solution. Later, ammonium metavanadate $\left(\mathrm{NH}_{4} \mathrm{VO}_{3}\right)$ solution, in the required stoichiometry, was added very slowly into the above solution and the $\mathrm{pH}$ was adjusted to around 10. As a result, yellow precipitate was obtained. The precipitate was filtered, repeatedly rinsed with distilled water and finally washed twice with ethanol. The obtained solid product was dried for $1 \mathrm{~h}$ at $100^{\circ} \mathrm{C}$ followed by calcination at $600^{\circ} \mathrm{C}$ for $3 \mathrm{~h}$. The above procedure without the dopant solution is adapted to prepare pure $\mathrm{ZnO}$. The doping concentrations of vanadium are expressed in at $\%$.

\subsection{Characterization techniques}

The phase stability and composition were checked by X-ray diffraction using Rigaku Ultima IV high-resolution X-ray diffractometer equipped with $\mathrm{Cu}-\mathrm{K} \alpha$ radiation. Magnetic measurements were carried out at room temperature using PMC MicroMag 3900 model Vibrating Sample Magnetometer (VSM) equipped with a 1 Tesla magnet. Chemical composition was determined by energy dispersive X-ray spectroscopy (EDX) attached to the scanning electron microscope (SEM) ZEISS EVO LS10.

Table 1. Magnetic parameters obtained from ab-initio calculations for pure and V-doped $\mathrm{ZnO}$ system.

\begin{tabular}{lcccc}
\hline Composition & Moment $d\left(\mu_{\beta}\right)$ & Moment $P\left(\mu_{\beta}\right)$ & $\Delta E=E_{\text {DLM }}-E_{\mathrm{FM}}(\mathrm{mRy})$ & $T_{\mathrm{C}}(\mathrm{K})$ \\
\hline $\mathrm{Zn}_{0.97} \mathrm{~V}_{0.03} \mathrm{O}$ & 0.80 & -0.00021 & 0.0000852 & 299.5 \\
$\mathrm{Zn}_{0.95} \mathrm{~V}_{0.05} \mathrm{O}$ & 0.75 & -0.00101 & 0.0002112 & 445.4 \\
$\mathrm{Zn}_{0.90} \mathrm{~V}_{0.10} \mathrm{O}$ & 0.53 & -0.00323 & 0.0001235 & 130.3 \\
$\mathrm{Zn}_{0.88} \mathrm{~V}_{0.12} \mathrm{O}$ & 0.32 & -0.00201 & 0.0001256 & 110.4 \\
$\mathrm{Zn}_{0.85} \mathrm{~V}_{0.15} \mathrm{O}$ & 0.1 & -0.00312 & 0.0001401 & 98.54 \\
\hline
\end{tabular}


(a)

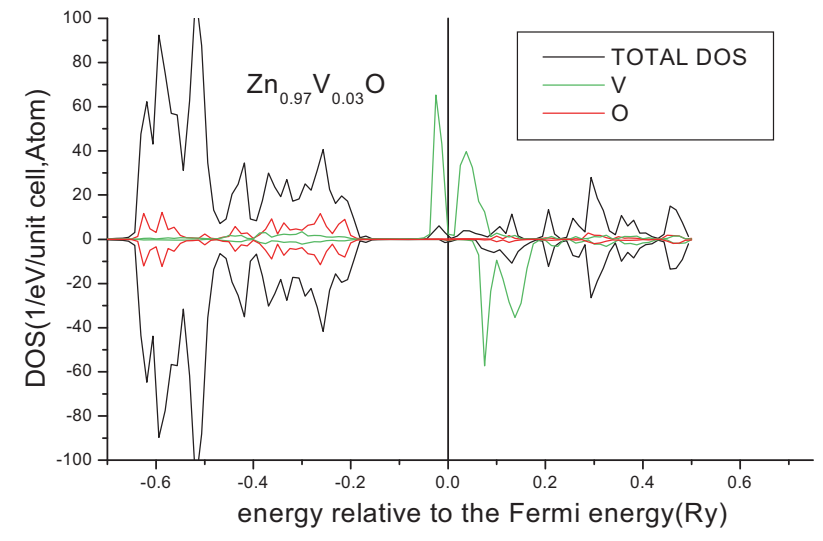

(b)

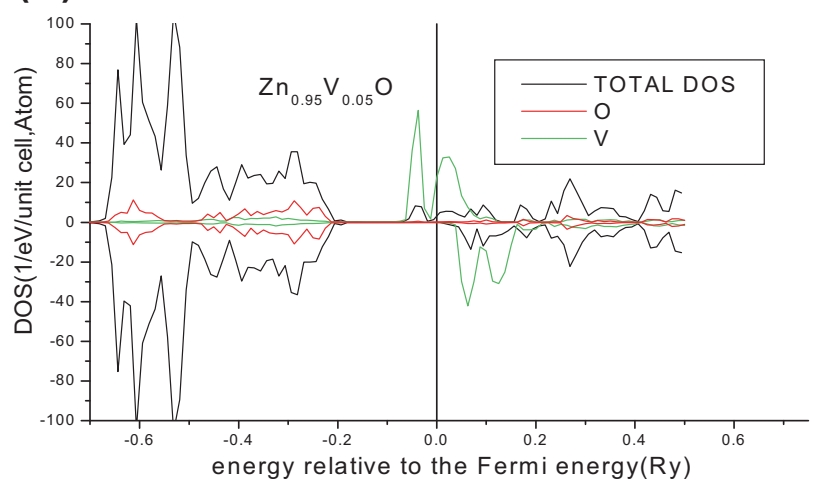

Figure 2. (a and b) Total and local DOS for the ferromagnetic $\mathrm{Zn}_{1-x} \mathrm{~V}_{x} \mathrm{O}$ with $x=0.03$ and 0.05 .

\section{Results and discussion}

\subsection{Ab-initio calculations}

Ferromagnetism and antiferromagnetism are explained by the interaction between $\mathrm{O}$ (p-orbitals) and $\mathrm{V}$ (d-orbitals) atoms in $\mathrm{V}$-doped $\mathrm{ZnO}$ system. Incomplete d-orbitals of $\mathrm{V}$ atoms interact directly and become the main source of magnetic moment in $\mathrm{V}$-doped $\mathrm{ZnO}$. This in turn decides the FM or antiferromagnetic behaviour of the studied system, as described earlier by Zener [35]. In the present case, p-orbital of $\mathrm{O}$ atom is responsible for the origin of the magnetic moment. Thereby, it can be concluded that $\mathrm{V}$-doped $\mathrm{ZnO}$ system should be an anti-FM or FM material. From figure $2 \mathrm{a}$ and $\mathrm{b}$, it is observed that the impurity band lies within the bandgap and is composed of $\mathrm{d}$ orbitals of $\mathrm{V}$ atom. Hence, it is inferred that the $3 \mathrm{~d}$-band of the up- or the down-spin states is not fully occupied. If neighbouring TM atoms have parallel magnetic moments, then hopping of 3d-elctron in the partially occupied 3d-orbitals of the TM to the $3 \mathrm{~d}$-orbtials of neighbouring TM is allowed. Hence, kinetic energy of the d-electron is lowered by hopping in the FM state. It is known as double-exchange mechanism. As neighbouring TMs have antiparallel magnetic moments, energy gain of this kind is not expected. Akai $[15,36]$ had
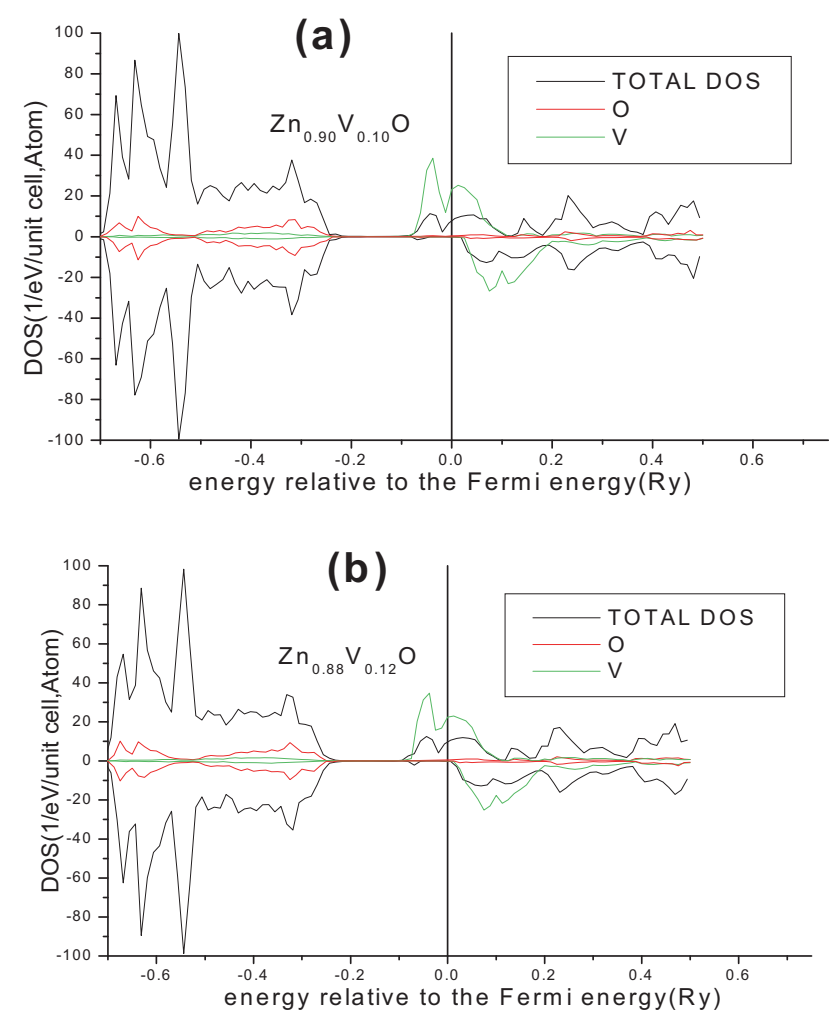

Figure 3. (a and b) Total and local DOS for the ferromagnetic $\mathrm{Zn}_{1-x} \mathrm{~V}_{x} \mathrm{O}$ with $x=0.10$ and 0.12 .

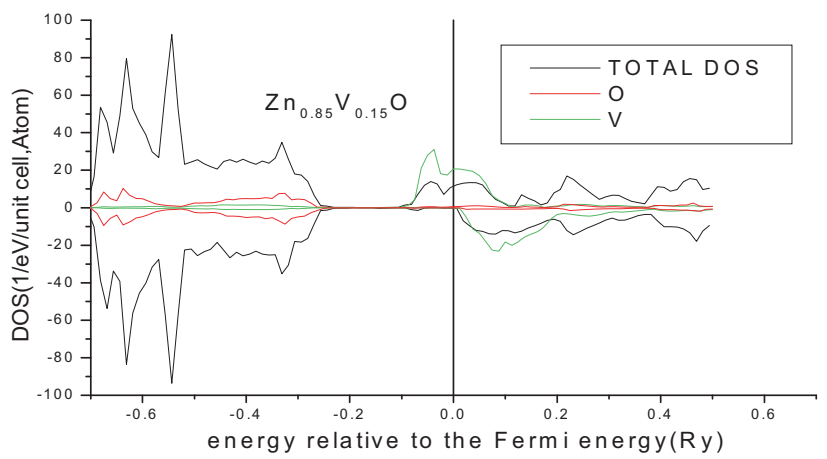

Figure 4. Total and local DOS for the ferromagnetic $\mathrm{Zn}_{1-x} \mathrm{~V}_{x} \mathrm{O}$ with $x=0.15$.

already pointed out this kind of mechanism in (In, Mn)As system. Therefore, a similar kind of mechanism in TMdoped $\mathrm{ZnO}$ systems based on half-metallic ferromagnetism is expected. Moreover, the bandgap of V-doped system was found to decrease slightly. Another important result is that the above system has zero DOS at Fermi energy for low V concentrations, while it is half-metallic for higher concentrations. Hence, in V-doped $\mathrm{ZnO}$, the stability of the ferromagnetism as a function of $\mathrm{V}$ concentrations was studied. It is found that $\mathrm{V}$ doping element can induce a magnetic moment of about 0.80 $\mu \mathrm{B}$ per V-dopant. At higher V content (10, 12 and 15\% V), due to the FM RKKY mechanism, FM behaviour is expected. 


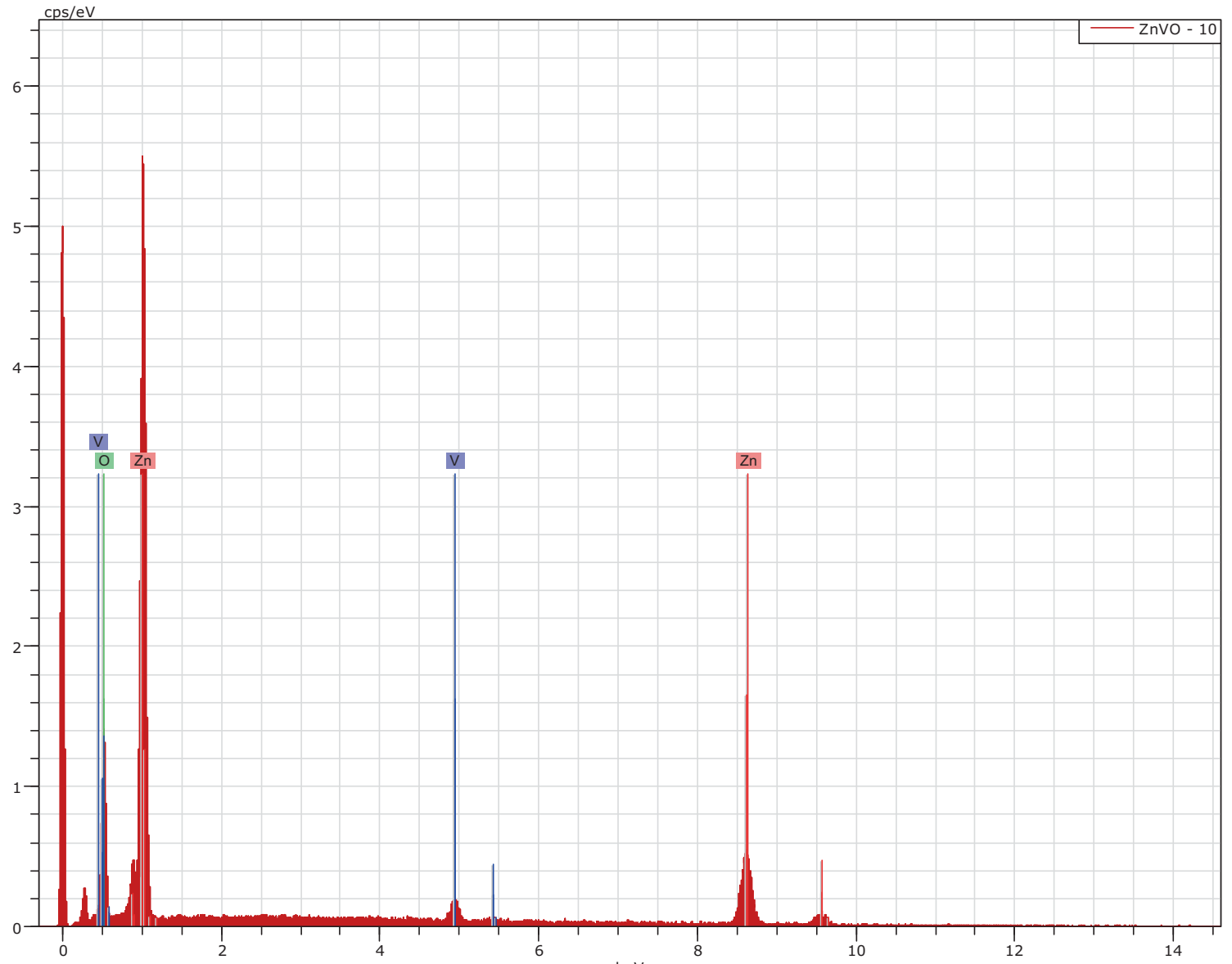

Figure 5. EDS spectrum of $10 \% \mathrm{~V}$-doped $\mathrm{ZnO}$ as obtained from EDS analysis.

The above-obtained results suggest that $\mathrm{V}$ is in the low spin state, and the spin state is independent of the concentration of $\mathrm{V}$ up to high concentrations.

Half-metallicity is achieved, as the Fermi level is located at the peak of the minority-spin band and a gap opened in the majority spin band (figure $3 a$ and b). From figure $2 a$, it is observed that the $3 \mathrm{~d}$-components of $\mathrm{V}$ have very small contribution. The top band dispersion is due to the $\mathrm{p}$-d hybridization. Thus more than the $3 \mathrm{~d}$ electrons, the spin exchange splitting of O-2p play a significant role to induce the obtained ferromagnetism. Figure 4 shows DOS of $\mathrm{V}$-doped $\mathrm{ZnO}$ for $15 \% \mathrm{~V}$ concentration. It is inferred that the $\mathrm{V}$ substitution starts the exchange-split impurity states in the bandgap and with increasing $\mathrm{V}$ concentration, the size of impurity states increases. Fermi energy $\left(E_{F}\right)$ passes through the minority spin impurity states, indicating that the system is half-metallic. V $3 \mathrm{~d}$-state hybridized with the $2 \mathrm{p}$ states of $\mathrm{O}$ atoms around $\mathrm{V}$ makes the impurity states in the bandgap.

From figure 4, it is clear that the hybridization occurs between the exchange-split V $3 d$-states and O-2p states at the top of the valance band. It is also found that the conduction band of the impurity is partially spin-polarized. The spin magnetic moment values given in table 1 indicates a decrease from
Table 2. Chemical analysis as determined by EDS method.

\begin{tabular}{lccc}
\hline Composition & $\mathrm{Zn}($ at.\%) & $\mathrm{V}$ (at.\%) & O (at.\%) \\
\hline $\mathrm{ZnO}$ & 52.93 & 0.00 & 47.07 \\
$\mathrm{Zn}_{0.97} \mathrm{~V}_{0.03} \mathrm{O}$ & 56.17 & 2.37 & 41.46 \\
$\mathrm{Zn}_{0.95} \mathrm{~V}_{0.05} \mathrm{O}$ & 56.09 & 4.16 & 39.76 \\
$\mathrm{Zn}_{0.90} \mathrm{~V}_{0.10} \mathrm{O}$ & 52.92 & 7.20 & 39.88 \\
$\mathrm{Zn}_{0.88} \mathrm{~V}_{0.12} \mathrm{O}$ & 49.41 & 7.92 & 42.67 \\
$\mathrm{Zn}_{0.85} \mathrm{~V}_{0.15} \mathrm{O}$ & 53.02 & 8.52 & 38.45 \\
\hline
\end{tabular}

$3 \%(0.80 \mu \mathrm{B})$ to $15 \%(0.1 \mu \mathrm{B})$, then remains monotonically. It is initially assumed that the magnetic moment does not depend on the concentration of $\mathrm{V}$, as the free carriers do not contain spins. However, the calculations in this study clearly show the decrease of the spin magnetic moment with the increase in $\mathrm{V}$ concentration within $\mathrm{ZnO}$. The reason is attributed to the finite exchange splitting of the conduction band.

\subsection{Chemical analysis}

EDX analysis (figure 5 and table 2) shows the presence of $\mathrm{Zn}, \mathrm{V}$ and $\mathrm{O}$ elements only, which confirms the purity of the 
as-prepared powder compositions. It is also found that the $\mathrm{V}$ content increases with increase in nominal concentration, whereas its value always remains smaller. This may be due to the following reasons: (i) some amount of starting V-precursor did not dissolve and react well during preparation, later it was removed during washing process; and (ii) the chemical

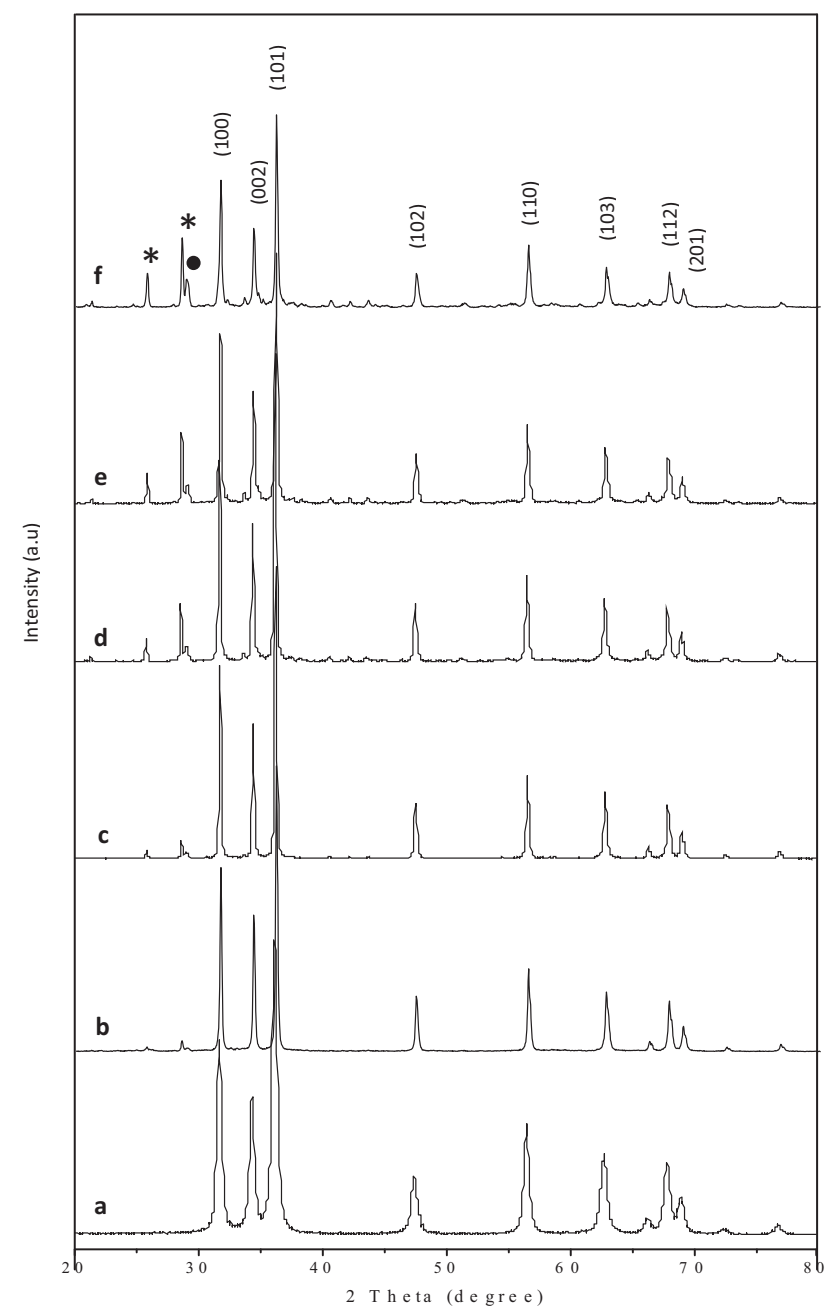

Figure 6. Evolution of $\mathrm{X}$-ray diffraction patterns of V-doped $\mathrm{ZnO}$ system: (a) pure $\mathrm{ZnO}$; (b) $\mathrm{Zn}_{0.97} \mathrm{~V}_{0.03} \mathrm{O}$; (c) $\mathrm{Zn}_{0.95} \mathrm{~V}_{0.05} \mathrm{O}$; (d) $\mathrm{Zn}_{0.90} \mathrm{~V}_{0.10} \mathrm{O}$; (e) $\mathrm{Zn}_{0.88} \mathrm{~V}_{0.12} \mathrm{O}$ and (f) $\mathrm{Zn}_{0.85} \mathrm{~V}_{0.15} \mathrm{O}$. reactions involved to form $\mathrm{Zn}_{1-x} \mathrm{~V}_{x} \mathrm{O}$ system were not fully completed.

\subsection{Structural analysis}

Figure 6 shows XRD patterns for pure and V-doped ZnO samples. It is observed that all diffraction peaks are indexed within the hexagonal wurtzite structure [37]. The impurity phases are marked as '*' and ' $\bullet$ ' in the $15 \%$ vanadium-doped $\mathrm{ZnO}$ sample (figure 6f), and are indexed as zinc divanadium oxide $\left(\mathrm{ZnV}_{2} \mathrm{O}_{6}\right)$ and $\mathrm{Zn}_{4} \mathrm{~V}_{2} \mathrm{O}_{9}$, respectively. All the peaks appearing at $2 \theta=31.63,34.28,36.11,47.42,56.49,62.76,67.82$ and 68.95 can be attributed to the (100), (002), (101), (102), (110), (103), (112) and (201) planes of $\mathrm{ZnO}$, respectively. Scherrer's formula is used to calculate the crystallite size [38] and it is found to be $15 \mathrm{~nm}$ for pure $\mathrm{ZnO}$ and 57, 51, 53, 45 and $45 \mathrm{~nm}$ for $\mathrm{V}$-doped $\mathrm{ZnO}$ (table 3 ). From figure $7 \mathrm{a}$, it is observed that the crystallite size increases upto $3 \% \mathrm{~V}$ loading then decreases slightly. This may be due to the surface temperature, which would have affected the molecular concentration. It makes the growth of the tiny crystals at its surface and hence reduces the amount of liberated heat. Thus, it increases both the molecular concentration at the crystal surface and grain growth at 3\% loaded V sample. From the results, it is found that the crystallite size has decreased from 5 to $12 \%$ loaded $\mathrm{V}$. It can also be associated with the high energy required for $\mathrm{V}^{5+}$ ions to enter into $\mathrm{ZnO}$ lattice, so that it gets substituted for the complete grain crystallization and growth.

The determination of lattice parameters, strain and crystallite size has been achieved by the refinements of XRD patterns using the Rietveld method. The strain varies in the range $0.090-0.134 \%$, which represents a variation of $33 \%$ and an average value around $0.112 \%$ (figure $7 \mathrm{~b}$ ). This is originated from the reduction in the ionic radius; the doping element $\mathrm{V}^{5+}(0.68 \mathrm{~nm})$ is smaller than $\mathrm{Zn}^{2+}(0.88 \mathrm{~nm})$. In fact, this may cause crystal structure deformation (distortion), which in turn will influence the change of lattice parameters (figure 7c). Table 3 shows the results of change in $\mathrm{ZnO}$ lattice parameters and lattice constants at various $\mathrm{V}$ doping concentrations. For $12 \% \mathrm{~V}$ loaded sample, the lattice parameters $a$ and $c$ decrease when compared with the standard data for $\mathrm{ZnO}$ (JCPDS No. $80-0074)$, confirming the partial substitution of $\mathrm{V}^{5+}$ ion in $\mathrm{Zn}^{2+}$ ions within $\mathrm{ZnO}$ host lattice.

Table 3. Rietveld analysis results for pure and V-doped $\mathrm{ZnO}$ system.

\begin{tabular}{lcccc}
\hline & & & \multicolumn{2}{c}{ Lattice parameters } \\
\cline { 4 - 5 } Samples & Crystallite size, $D(\mathrm{~nm})$ & Strain $(\%)$ & $a(\AA)$ & $c(\AA)$ \\
\hline $\mathrm{ZnO}$ & 15 & 0.090 & 3.2582 & 5.2200 \\
$\mathrm{Zn}_{0.97} \mathrm{~V}_{0.03} \mathrm{O}$ & 57 & 0.106 & 3.2547 & 5.2134 \\
$\mathrm{Zn}_{0.95} \mathrm{~V}_{0.05} \mathrm{O}$ & 51 & 0.122 & 3.2542 & 5.2122 \\
$\mathrm{Zn}_{0.90} \mathrm{~V}_{0.10} \mathrm{O}$ & 53 & 0.099 & 3.2552 & 5.2118 \\
$\mathrm{Zn}_{0.88} \mathrm{~V}_{0.12} \mathrm{O}$ & 45 & 0.134 & 3.2536 & 5.2118 \\
$\mathrm{Zn}_{0.85} \mathrm{~V}_{0.15} \mathrm{O}$ & 45 & 0.100 & 3.2552 & 5.2140 \\
\hline
\end{tabular}



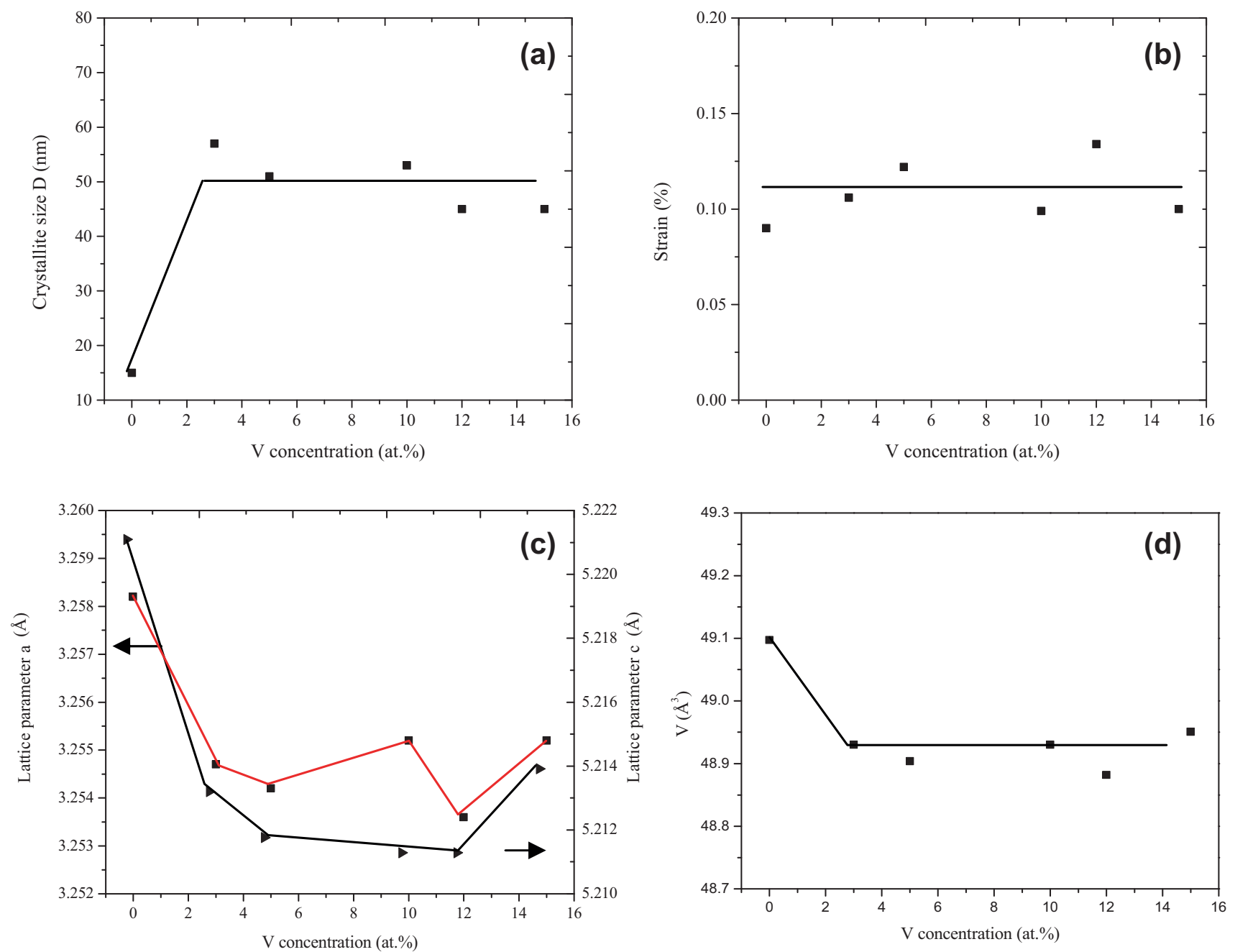

Figure 7. Evolution of lattice parameters of $\mathrm{Zn}_{1-x} \mathrm{~V}_{x} \mathrm{O}$ system as obtained by Rietveld refinements.

In DMS, it is an interesting fact that the dopant replaces the ions of the host lattice. Owing to charge matching, in both pure and $\mathrm{V}$-doped $\mathrm{ZnO}, \mathrm{Zn}^{2+}$ ions in the lattice are substituted by the doping concentrations of $2+$ oxidation state. We know that the ionic radius of $\mathrm{V}^{5+}$ is smaller than for $\mathrm{Zn}^{2+}$, there would be substitution of $\mathrm{V}^{5+}$ in $\mathrm{Zn}^{2+}$ lattice and thus there is a reduction in the values of lattice parameters; i.e., ionic radii reduction and mismatch may occur [37]. At higher doping of $12 \%$, there would be definitely substitution of $\mathrm{V}^{5+}$ ions. The possibility to form localized groups of $\mathrm{V}$ atoms increases because of the lattice defects, which are caused by the increase in $\mathrm{V}$ content. Hence, the crystal structure is weakened, as $\mathrm{ZnO}$ lattice is distorted because of the non-uniform distribution of $\mathrm{V}^{5+}$ ions. Hence, the crystal quality is deteriorated and grain size is reduced [39].

It is also noted that the lattice volume of pure $\mathrm{ZnO}$ drastically decreases after $3 \% \mathrm{~V}$-loading, then remains constant at higher doping (figure 7d). One reason may be because of the anisotropic changes in the lattice parameters (figure 7a and c) occurring due to the random site occupancy of $\mathrm{V}^{5+}$ into $\mathrm{Zn}^{2+}$

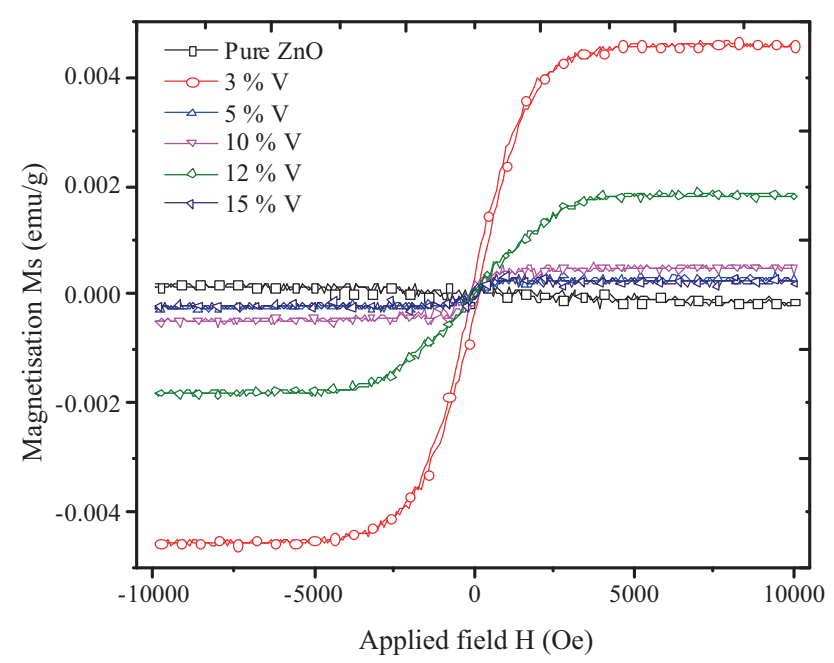

Figure 8. $M-H$ hysteresis loops of $\mathrm{V}$-doped $\mathrm{ZnO}$ system. 

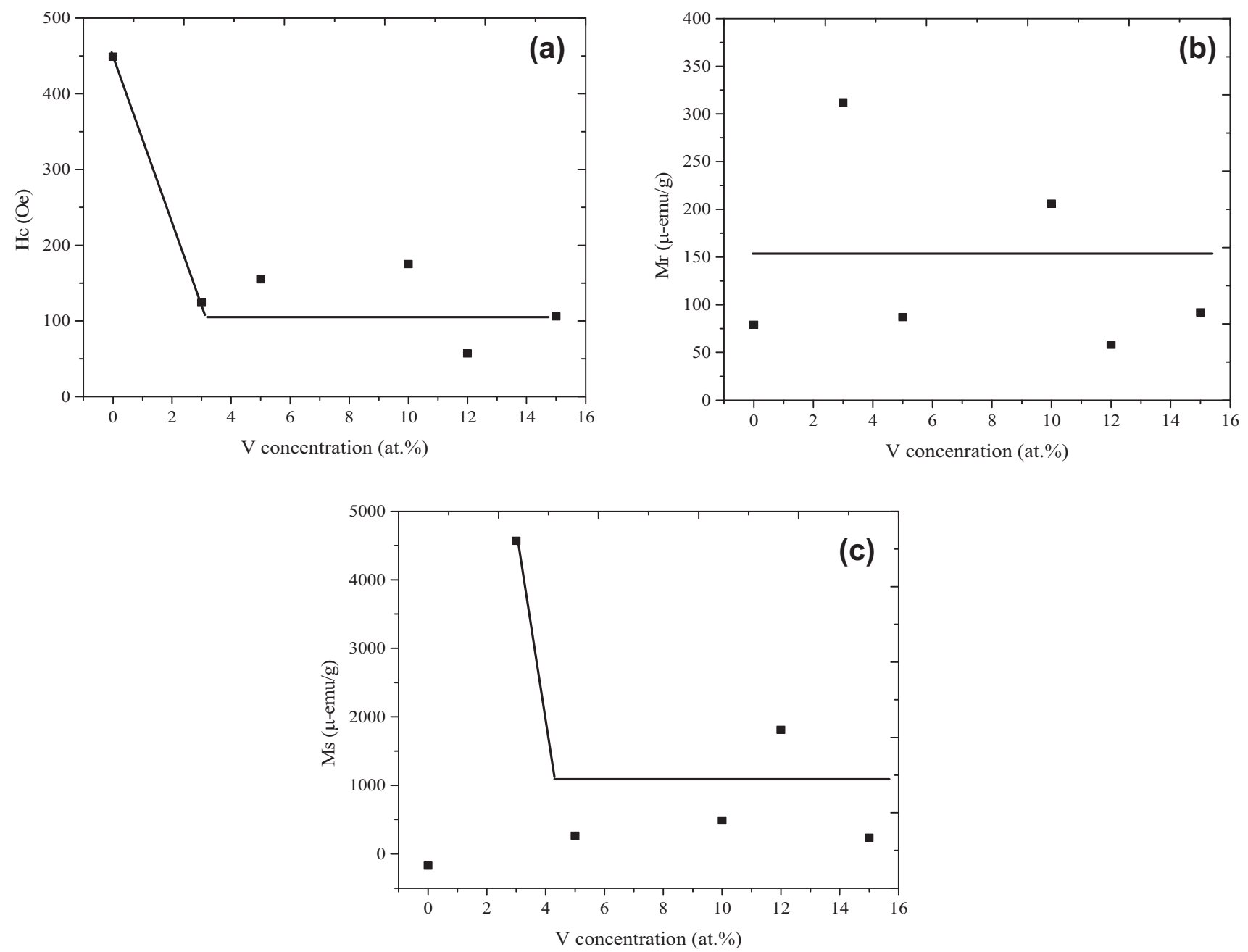

Figure 9. Experimental magnetic parameters obtained for pure and V-doped $\mathrm{ZnO}$ system.

within $\mathrm{ZnO}$ crystal lattice by forming a disordered $(\mathrm{Zn}, \mathrm{V}) \mathrm{O}$ solid solution. Another reason may be the change in the initial valence $(+5)$ into lower valence, oxidation during synthesis and/or during subsequent annealing at $600^{\circ} \mathrm{C}$ for $3 \mathrm{~h}$ occurring at higher $\mathrm{V}$ concentrations $\left(\mathrm{V}^{4+}=0.72, \mathrm{~V}^{3+}=0.78\right.$ and $\mathrm{V}^{2+}=0.93 \mathrm{~nm}$ ).

\subsection{Magnetic properties}

Figure 8 shows the magnetization-field $(M-H)$ curves as obtained by VSM measurements of pure and 3, 5, 10, 12 and $15 \% \mathrm{~V}$-doped $\mathrm{ZnO}$ samples. It can be observed that there is an overlap of diamagnetic component with a FM behaviour for all compositions. The cause of diamagnetic behaviour in our samples is not known. The $M-H$ curves showed weak magnetic behaviour for pure and $\mathrm{V}$-doped $\mathrm{ZnO}$ samples. The presence of $\mathrm{FM}$ behaviour denotes that the $\mathrm{V}^{5+}$ ions have been substituted into $\mathrm{Zn}^{2+}$ sites without altering the original wurtzite structure of $\mathrm{ZnO}$ [40]. The $M-H$ curves show diamagnetic nature for pure $\mathrm{ZnO}$, while the observed $\mathrm{FM}$ ordering weakens with increasing V-doping concentration.

It can be noticed that the magnetic moment $\left(\mathrm{emu}^{-1}\right)$ increases with the increase in the $\mathrm{V}$ loading as shown in figure $9 \mathrm{a}-\mathrm{c}$ and table 4 . The saturation magnetization decreases significantly when $\mathrm{V}$ loading is increased, reaching a maximum value of $4571 \mu \mathrm{emu} \mathrm{g}^{-1}$ at $3 \% \mathrm{~V}$. Meanwhile, a notable difference is observed in the magnetic parameters at different $\mathrm{V}$ loading.

At higher loading of $\mathrm{V}^{5+}$ ions, the magnetic moment decreases, as may be more dopant-dopant associations occur. Hence, the present magnetic ordering may also originate from $\mathrm{V}$ clusters. However, equivalent signal of $\mathrm{V}$ clusters was not observed by XRD as mentioned above (single phase for low V concentration, while secondary phase appear only for higher doping; i.e., 15\%) and the lattice parameters are found to decrease with increase in $\mathrm{V}$ content, which indicate that $\mathrm{V}$ is incorporated into $\mathrm{ZnO}$ lattice. This proposed mechanism associated with magnetic ordering even though due to the controversial results reported in the literature, as there is no 
Table 4. Experimental magnetic parameters obtained for pure and V-doped $\mathrm{ZnO}$ system.

\begin{tabular}{lcccc}
\hline Samples & Magnetic character & $H_{\mathrm{c}}(\mathrm{Oe})$ & $M_{\mathrm{r}}\left(\mu \mathrm{emu} \mathrm{g}{ }^{-1}\right)$ & $M_{\mathrm{s}}\left(\mu \mathrm{emu} \mathrm{g}^{-1}\right)$ \\
\hline $\mathrm{ZnO}$ & Diamagnetic & 449 & 79 & -172 \\
$\mathrm{Zn}_{0.97} \mathrm{~V}_{0.03} \mathrm{O}$ & Ferromagnetic & 124 & 312 & 4571 \\
$\mathrm{Zn}_{0.95} \mathrm{~V}_{0.05} \mathrm{O}$ & Ferromagnetic & 155 & 87 & 265 \\
$\mathrm{Zn}_{0.90} \mathrm{~V}_{0.10} \mathrm{O}$ & Ferromagnetic & 175 & 206 & 487 \\
$\mathrm{Zn}_{0.88} \mathrm{~V}_{0.12} \mathrm{O}$ & Ferromagnetic & 57 & 58 & 1811 \\
$\mathrm{Zn}_{0.85} \mathrm{~V}_{0.15} \mathrm{O}$ & Ferromagnetic & 106 & 92 & 234 \\
\hline
\end{tabular}

single theory that can explicitly explain the exact origin of ferromagnetism in all oxide DMS [41-43]. Long-range FM ordering is achieved in the present case, as the interaction among the ions within the polaronic radius would be FM. Hence, ferromagnetism is resulted from intrinsic factor and correlated with structural defects of V-doped $\mathrm{ZnO}$ system $[44,45]$. During thermal annealing process of our samples, structure defects are formed, such as oxygen vacancies [41], and the interfacial defects can overlap with dopant vanadium ions. They also indicate a FM coupling between the dopant spins [46]. Moreover, it can be observed that the coercivity $\left(H_{\mathrm{c}}\right.$, figure $\left.7 \mathrm{a}\right)$ decreases drastically from 449 Oe for undoped $\mathrm{ZnO}$ up to an average value around 100 Oe with increase in $\mathrm{V}$ doping concentration, whereas remanence fluctuates around a mean value of about $150 \mu \mathrm{emu} \mathrm{g}^{-1}$ (figure $7 \mathrm{~b}$ ). The above anisotropic changes may be associated with numerous parameters, such as increase of particle size, smaller ionic radius of the doping element causing lattice distortion, anisotropic variation of lattice parameters, valence of the doping element $\left(\mathrm{V}^{+5}\right)$, presence of secondary phases $\left(\mathrm{ZnV}_{2} \mathrm{O}_{6}\right.$ and $\left.\mathrm{Zn}_{4} \mathrm{~V}_{2} \mathrm{O}_{9}\right)$, with their amount varying considerably with the variation of doping concentrations, etc.

\section{Conclusion}

$\mathrm{V}$-doped $\mathrm{ZnO}$ system with various $\mathrm{V}$ concentrations (3, 5, 10,12 and $15 \%$ ) has been studied using density functional theory. The spin magnetic moment is dependent on the concentration of $\mathrm{V}$ and the results denote the presence of three different states of $\mathrm{V}$ spin magnetic moment. The ferromagnetism observed in V-doped $\mathrm{ZnO}$ system is explained on the basis of RKKY mechanism and the atomic spin polarization. All compositions exhibit a hexagonal wurtzite crystal structure, as confirmed by Rietveld analysis. In addition, both crystallite size and lattice parameters vary with $\mathrm{V}$ doping concentration. Room temperature magnetic measurements reveal FM behaviour for all studied compositions, meanwhile saturation magnetization is optimum at $3 \% \mathrm{~V}$, and then decreases.

\section{References}

[1] Ohno H, Shen A, Matsukura F, Oiwa A, Endo A, Katsumoto S et al 1996 Appl. Phys. Lett. 69363
[2] Nazmul A M, Amemiya T, Shuto Y, Sugahara S and Tanaka M 2005 Phys. Rev. Lett. 95017201

[3] Sharma P, Gupta A, Rao K V, Owens F J, Sharma R, Ahuja R et al 2003 Nat. Mater. 2673

[4] Matsumoto Y, Murakami M, Shono T, Hasegawa T, Fukumura T, Kawasaki M et al 2001 Science 291854

[5] Mi W B, Jiang E Y and Bai H L 2008 Acta Mater. 56 3511

[6] Pearton S J, Norton D P, Ivill M P, Hebard A F, Zavada J M, Chen W M et al 2007 IEEE Trans. Electr. Dev. 541040

[7] Wolf S A, Awschalom D D, Buhrman R A, Daughton J M, Von Molnàr S, Roukes M L et al 2001 Science 2941488

[8] Furdyna J K 1988 J. Appl. Phys. 64 R29

[9] Ohno H 1998 Science 281951

[10] Park Y D, Hanbicki A T, Erwin S C, Hellberg C S, Sullivan J M, Mattson J E et al 2002 Science 295651

[11] Medvedkin G A, Ishibashi T, Nishi T, Hayata K, Hasegawa Y and Sato K 2000 Jpn. J. Appl. Phys. 39 L949

[12] Zhao Y J, Picozzi S, Continenza A, Geng W T and Freeman A J 2002 Phys. Rev. B 65094415

[13] Dietl T, Ohno H, Cibert J and Ferrand D 2000 Science 287 1019

[14] Inoue J, Nonoyama S and Itoh H 2000 Phys. Rev. Lett. 85 4610

[15] Akai H 1998 Phys. Rev. Lett. 813002

[16] Venkatesan M, Fitsgerald C B, Lunney J G and Coey J M D 2004 Phys. Rev. Lett. 93177206

[17] Wu P, Saraf G, Lu Y, Hill D H, Gateau R, Wielunski L et al 2006 Appl. Phys. Lett. 89012508

[18] Song C, Geng K W, Zeng F, Wang X B, Shen Y X, Pan F et al 2006 Phys. Rev. B 73024405

[19] Hong N H, Sakai J, Huong N T, Poirot N and Ruyter A 2005 Phys. Rev. B 72045336

[20] Kittilstved K R, Norberg N S and Gamelin D R 2005 Phys. Rev. Lett. 94147209

[21] Wang Q, Sun Q, Jena P and Kawazoe Y 2004 Phys. Rev. B 70 052408

[22] Karmakar V, Mandal S K, Kadam R M, Paulose P L, Rajarajan A K, Nath T K et al 2007 Phys. Rev. B 75144404

[23] Kolesnik S, Dabrowski B and Mais J 2004 J. Appl. Phys. 95 2582

[24] Kolesnik S and Dabrowski B 2004 J. Appl. Phys. 965379

[25] Lawes G, Risbud A S, Ramirez A P and Seshadri R 2005 Phys. Rev. B 71045201

[26] Kohan A F, Ceder G, Morgan D and Van de Walle C G 2000 Phys. Rev. B 6115019

[27] Gopal P and Spaldin N A 2006 Phys. Rev. B 74 094418 
[28] Spaldin N A 2004 Phys. Rev. B 69125201

[29] Chambers S A, Droubay T C, Wang C M, Rosso K M, Heald S M, Schwartz D A et al 2006 Mater. Today 928

[30] Sharma P, Sreenivas K and Rao K V 2003 J. Appl. Phys. 93 3963

[31] Sharma P and Sreenivas K 2003 Appl. Phys. Lett. 83 3617

[32] MACHIKANEYAMA2002v08 Akai H Department of Physics, Graduate School of Science, Osaka University, Machikaneyama 1-1, Toyonaka 560-0043, Japan, akai@phys.sci.osaka-u.ac.jp

[33] Arul Mary J, Judith Vijaya J, Bououdina M, John Kennedy L, Dai J H and Y. Song 2015 Physica E: Low-dimens. Syst. Nanostruct. 66209

[34] Karamat S, Rawat R S, Lee P, Tan T L, Ramanujan R V and Zhou W 2010 Appl. Surf. Sci. 2562309

[35] Zener V 1951 Phys. Rev. B 81440

[36] Sato K and Katayama-Yoshida H 2000 Jpn. J. Appl. Phys. 39 L555
[37] Karamat S, Rawat R S, Lee P, Tan T L, Ramanujan R V and Zhou W 2010 Appl. Surf. Sci. 2562309

[38] Freedsman J J, Kennedy L J, Kumar R T, Sekaran G and Vijaya J J 2010 Mater. Res. Bull. 451481

[39] Naydenova T S, Atanasov P, Koleva M, Nedialkov N, Perriere J, Defourneau D et al 2010 Thin Solid Films 5185505

[40] Shin S, Suga S, Taniguchi M, Fujisawa M, Kanzaki H, Fujimori A et al 1990 Phys. Rev. B 414993

[41] Coey J M D, Venkatesan M and Fitzgerald C B 2005 Nat. Mater. 4173

[42] Griffin K A, Pakhomov A B, Wang C M, Heald S M and Krishnan K M 2005 Phys. Rev. Lett. 22157204

[43] Archer P I and Gamelin D R 2006 J. Appl. Phys. 99 08M107

[44] Liu S H, Hsu H S, Lin C R, Lue C S and Huang J C A 2007 Appl. Phys. Lett. $\mathbf{9 0} 222505$

[45] Naeem M, Hasanain S K, Kobayashi M, Ishida Y, Fujimori A, Buzby S et al 2006 Nanotech. 172675

[46] Tian Z M, Yuan S L, Yin S Y, Zhang S Q, Xie H Y, Miao J H et al 2008 J. Magn. Magn. Mater. 320 L5 